\title{
The Properties of Sprayed Nanostructured P-Type CuI Films for Dye-Sensitized Solar Cells Application
}

\author{
M. N. Amalina, N. A. Rasheid, and M. Rusop \\ NANO-ElecTronic Centre (NET), Faculty of Electrical Engineering, Universiti Teknologi MARA (UiTM), \\ 40450 Shah Alam, Malaysia \\ Correspondence should be addressed to M. N. Amalina, amalina.muhamad@gmail.com
}

Received 19 May 2012; Accepted 2 July 2012

Academic Editor: Yao Liu

Copyright ( $) 2012$ M. N. Amalina et al. This is an open access article distributed under the Creative Commons Attribution License, which permits unrestricted use, distribution, and reproduction in any medium, provided the original work is properly cited.

In our experiments, we provide a new approach for depositing $\mathrm{CuI}$ (inorganic compound) thin films using the mister atomizer technique. The $\mathrm{CuI}$ solution was sprayed into fine droplets using argon as a carrier gas at different solution concentrations. The solution sprayed was $50 \mathrm{ml}$ for all samples with substrate temperature constant at $50^{\circ} \mathrm{C}$ during the deposition process. The result shows that the $\mathrm{CuI}$ thin film properties strongly depend on its precursor concentration. The structural properties were characterized by XRD with strong (111) orientation shows for all the CuI thin films. FESEM images revealed that all the CuI thin films deposited were uniform with the existence of nanostructured CuI particle. The EDX measurement confirms the existence of $\mathrm{Cu}: \mathrm{I}$ in the films. The nanostructured $\mathrm{CuI}$ will improve the penetration of p-type between the mesoporous matrix of $\mathrm{TiO}_{2}$ thin film. Promising conductivity value of about $10^{\circ} \mathrm{S} \mathrm{cm}^{-1}$ was obtained for CuI thin films deposited by this new deposition method. Low transmittance of below $50 \%$ was observed for all $\mathrm{CuI}$ thin films. The band gap energy obtained here was between $2.82 \mathrm{eV}$ and $2.92 \mathrm{eV}$ which is much smaller than the reported band gap which is $3.1 \mathrm{eV}$.

\section{Introduction}

In the 21st century, sustainable energy is among the hot topic discussed globally. With the increase in oil prices worldwide due to rapid depletion of resources, renewable energy sources are seen to provide promising alternatives which is no more reliance on oil, coal, and natural gas. Those renewable sources technologies include wind turbines, hydropower, wave and tidal power, solar cells, solar thermal, biomass-derived liquid fuels, and biomass-fired electricity generation. However, among of all these renewable energy, photovoltaic technology utilizing solar energy is the most promising one since the energy source is readily available. The most popular and commercially available type of solar cell is silicon-based solar cell. However, there are problems regarding its stability, scaling-up and cost. Dye-sensitized solar cells (DSSCs) are one of other many types of solar cells to replace silicon-based type. In 1991, O'Regan and Gratzel had successfully fabricated the dye-sensitized solar cell with efficiency of $11 \%$ based on nanocrystalline $\mathrm{TiO}_{2}$, $\mathrm{I}^{-} / \mathrm{I}^{3-}$ redox electrolyte and dye [1]. However, the use of liquid electrolyte leads to a several problems such as solvent evaporation, degradation, and seal imperfection [2]. Hence, quasi solid or solid state DSSC is introduced to replace the liquid electrolyte $[3,4]$. There are several inorganic based on copper compound materials such as $\mathrm{CuBr}$ [2], $\mathrm{CuSCN}$ [5], CuI [6] that are employed as a hole transport material (HTM) for regeneration of dye where electron is donated by the hole conductor.

$\mathrm{CuI}$ is water insoluble solid with three crystalline phases which are $\alpha, \beta, \gamma$. The $\alpha$-phase is cubic structure with high temperature of $392^{\circ} \mathrm{C}$, hexagonal $\beta$-phase is an ionic conductor with temperature between $392^{\circ} \mathrm{C}$ and $350^{\circ} \mathrm{C}$, and $\gamma$-phase is a cubic structure with a low temperature below $350^{\circ} \mathrm{C}$ which behaves as a p-type semiconductor with a band gap of $3.1 \mathrm{eV}$. There are several important aspects that need to be considered for a p-type semiconductor in DSSC. Firstly it must be able to transfer holes from the sensitizing dye after the dye has injected electrons into the $\mathrm{TiO}_{2}$. Next, it must be able to be deposited within the nanocrystalline layer and the method used for the deposition will not dissolve and degrading the monolayer of dye on the $\mathrm{TiO}_{2}$ nanocrystallites. 
Lastly, it must be transparent in the visible spectrum or it must be as efficient in electron injection as the dye during light absorptions $[7,8]$. Tennakone et al. fabricated the first DSSC using CuI as a hole conductor shows an efficiency of $2.4 \%[9]$.

In this research the mister atomizer technique was used for $\mathrm{CuI}$ thin film deposition. The mister atomizer is essentially the same film processing technique as so-called spray pyrolysis technique. The most commonly used precursors for spraying technique for an inorganic compound are nitrate, carbonate, sulfate, and chloride [10]. The morphological properties of CuI play an important role in improving the solid state dye-sensitized solar cells (SSDSSCs) performance since it determines the interfacial connection between the dyed $\mathrm{TiO}_{2}$ and $\mathrm{CuI}$ so that dye regeneration can occurs [11]. The opt-electrical properties of CuI affect the photoelectron conversion efficiency which depends on its conductivity and absorption ability of the material to circumvent the insufficient light absorption due to the limited inner surface area of the $\mathrm{TiO}_{2}$ and interfacial recombination due to the lack of substantial interfacial electric field. In this research, the $\mathrm{CuI}$ films properties were investigated and its suitability to be used as a hole conductor for SSDSSC was discussed.

\section{Methods}

The $2.5 \mathrm{~cm} \times 2.5 \mathrm{~cm}$ glass substrates were cleaned using acetone, methanol, and deionized water in the ultrasonic cleaner stage by stage at 10 minutes each. The deposition of $\mathrm{CuI}$ films onto the substrates were taken at room temperature by atomization technique. The CuI solution was prepared by mixing precursor $\mathrm{CuI}$ powder (ALDRICH, 98\%) with acetonitrile as a solvent. All chemicals were used without any further purification. The CuI solutions were stirred for 3 hours at room temperature. The glass substrates were preheated at $50^{\circ} \mathrm{C}$ for $10 \mathrm{~min}$ before the deposition process. The parameter investigated in this present research work is the molar concentration which varies form $0.05 \mathrm{M}$ to $0.5 \mathrm{M}$. The solution was then sprayed in fine droplets using argon as a carrier gas. The solution sprayed was $50 \mathrm{~mL}$ for all samples. The deposition takes for 15 minutes at a constant flow rate of $50 \mathrm{~mL} / 15 \mathrm{~min}$ for all samples. After the spraying of $\mathrm{CuI}$ solutions, the films were dried at $50^{\circ} \mathrm{C}$ for $10 \mathrm{~min}$ to evaporate the solvent. The characterizations were done for structural, electrical, and optical properties. The structural properties of the thin films were investigated using X-ray diffractometer (XRD, PAN Analytical). The surface morphology of the films was observed with a field emission scanning electron microscope (JEOL JSM-J600F). The elemental analysis of the films was carried by energy dispersive $\mathrm{X}$-ray spectrometer attached to FESEM (JEOL JSM-J600F). The thin films have been characterized by 2 point probe current-voltage $(I-V)$ measurement by solar simulator (CEP 2000). Au was used as metal contacts for $I-V$ measurement and deposited using sputter coater (EMITECH K550X). The optical measurements of the films were characterized by JASCO UV-VIS-NIR spectrophotometer. The wavelength for the optical measurement was measured at wavelengths between $400 \mathrm{~nm}-800 \mathrm{~nm}$. The thickness of the thin film is characterized using surface profiler (VEECO DEKTAK 150). All of the measurements were done in room ambient.

\section{Results and Discussion}

3.1. Structural Properties. The XRD patterns were recorded for $\mathrm{CuI}$ thin film deposited onto glass substrates which varies from $0.05 \mathrm{M}$ to $0.5 \mathrm{M}$ and was shown in Figure 1. The diffraction peaks can be assigned to polycrystalline $\gamma$-phase $\mathrm{CuI}$ with zinc blend face centered cubic phase (JCPDS card no. 06-0246). There are several peaks observed in the series of Bragg reflections in XRD pattern which are (111), (222), (220), (311), (222), (331), (422). Therefore, it is confirmed that the CuI thin film is a hole transport semiconductor since it is a $\gamma$-phase rather than the $\alpha$-phase or $\beta$-phase which are an ionic conductors. From the figure, the (111) diffraction peak is much more intense than other any other peak. The high intensity of (111) orientation suggests that the (111) facets planes tend to be preferentially oriented parallel to the surface of the supporting substrate [12]. Sharper peaks were obtained for film at higher concentration compared to $0.05 \mathrm{M}$ which has very low intensity since it has the lowest thickness. Furthermore, the weak peak of $0.05 \mathrm{M}$ was due to the small crystallite size with full crystallization or evaporation of the acetonitrile during the deposition and not because of amorphous nature which originated from the incomplete pyrolysis of the precursor [13]. The instability of intensity at different molar concentration may be due to the thickness and defect of the thin film itself. However, the peak observed here is good enough to determine its suitability to be used as a hole conductor in DSSC [14]. Other than that, good crystallization of $\mathrm{CuI}$ film is observed even there is no annealing treatment is done on all of the samples. Therefore, it is confirmed that the CuI thin film deposited by mister atomizer is a hole transport semiconductor since it is a $\gamma$ phase rather than the $\alpha$-phase or $\beta$-phase which are ionic conductors.

Table 1 shows the thin film thickness, crystallite size, and grain size. The thickness was estimated using surface profiler measurement. The crystallite sizes were determined from the full width at half maximum (FWHM) of the XRD spectra while the grain sizes were obtained from the FESEM images. The crystallite sizes were calculated using Scherrer's formula, and the crystallite size $\mathrm{CuI}$ increased with the increase of molar concentration. At higher concentration $(0.5 \mathrm{M})$ the crystallite size is sharply decreased. The evaporation of individual fine droplets during the spray process attributed to the formation of smaller crystallite size [15]. For low concentration $(0.05 \mathrm{M})$ the mobility of ions is insufficient for growing, while at higher concentration $(0.5 \mathrm{M})$ the mobility of ions is higher and leads to crystal agglomerate destruction. Therefore, complete grain growth does not occur, which reduces the formation of crystallite size [16]. Besides that, the crystallites in $\mathrm{CuI}$ films normally will grow with time: however, for solid state DSSC application, the usage of CuI films in devices depends on stability against the crystallite growth. The thickness of the CuI thin film increased as the 
TABle 1: Thickness, crystallite size, and grain size of CuI at different molar concentration.

\begin{tabular}{|c|c|c|c|}
\hline Molar concentration $(\mathrm{M})$ & Thickness (nm) & Crystallite size $(\mathrm{nm})$ & Grain size $(\mathrm{nm})$ \\
\hline 0.050 & $5.28 \times 10^{2}$ & 6.40 & \multirow{5}{*}{ Approximately $30 \mathrm{~nm}$ to $80 \mathrm{~nm}$} \\
\hline 0.075 & $9.63 \times 10^{2}$ & 41.2 & \\
\hline 0.100 & $12 \times 10^{2}$ & 37.6 & \\
\hline 0.250 & $33.8 \times 10^{2}$ & 55.1 & \\
\hline 0.500 & $65.6 \times 10^{2}$ & 29.6 & \\
\hline
\end{tabular}

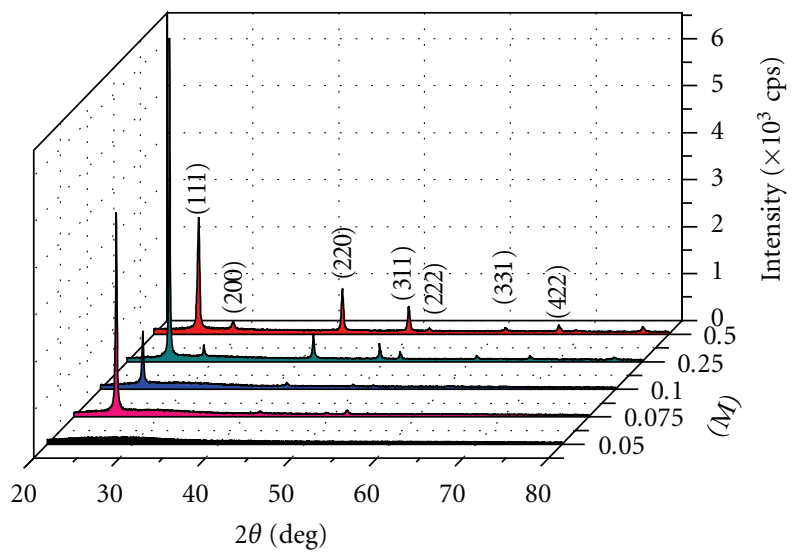

FIGURE 1: XRD spectra of CuI thin films at different molar concentration.

concentration increased. The thickness of the thin film affects the crystallinity, electrical, and optical properties of the thin film. The reported thickness for $\mathrm{CuI}$ for fabrication of solid state DSSC is around $3 \mu \mathrm{m}$ above the $\mathrm{TiO}_{2}$ layer [17].

The surface morphology images of $\mathrm{CuI}$ thin films obtained by FESEM are shown in Figure 2 From the figures, it could be understood that the surface morphology of $\mathrm{CuI}$ films depends on the solution concentration. The CuI thin films at $0.5 \mathrm{M}$ concentration show much more rougher surface with presence of many bigger grain sizes compared to other solution concentration. However, the grain sizes for all thin films are not uniform and it varies from $30 \mathrm{~nm}$ to $80 \mathrm{~nm}$. The concentration supposedly affects the grain size where higher grain size with lower grain boundaries should be achieved as the solution concentration increased. However, the variation of grain size in this research could be happened due to the agglomeration of smaller particles. The CuI particle (spherical) like structure was obtained as expected and this is in the good agreement by Yan et al. which also used spraying method for CuI deposition [18]. Therefore, the grain sizes observed by FESEM were the aggregations of smaller primary particles which are the crystallites which were too small to be observed in FESEM. The nanostructured $\mathrm{CuI}$ is favorable for electronic devices, for instance CuI can be used as hole conductor for solid state dye-sensitized solar cells (DSSCs). In solid state DSSC, the porous $\mathrm{TiO}_{2}$ ( $n$-type semiconductor) was used to increase high surface area for more electron movement. However, the problem of hole transport material to fill the porous structure $\mathrm{TiO}_{2}$ is the bigger challenge [19]. Several crystal growth inhibitors such as 1-methyl-3ethyl-imidazolium thiocyanate (MEIT), triethylamine hydrothiocyanate (THT), and tetramethylethylene-diamine (TMED) is normally used in solid state DSSC application to control the crystal size by means to get nanosize of CuI [20-22]. The nanoparticle CuI obtained by using mister atomizer can be new way of depositing CuI onto the porous $\mathrm{TiO}_{2}$ for better interconnection to avoid recombination and hence gives better efficiency. The elemental analysis of $\mathrm{Cu}: \mathrm{I}$ is investigated by EDX analysis as shown in Figure 2(e). The EDX measurement confirms the existence of Cu:I in the films. The weak peak of Si and $\mathrm{O}$ shown in the EDX spectra is corresponded to the glass substrate material.

3.2. Electrical Properties. The electrical properties of $\mathrm{CuI}$ films were by using 2-point probe $I-V$ measurement. The voltage applied is in the range of $-5 \mathrm{~V}$ and $5 \mathrm{~V}$ and measured in dark and under illumination condition. The white bias light with intensity of $1000 \mathrm{Wm}^{-2}$ with illuminated area of $0.05 \mathrm{~cm}^{2}$ is used to observe the photoconductivity of $\mathrm{CuI}$ thin films and the data were recorded with solar simulator (CEP 2000). The metal contact used for the measurement is aurum (gold). From the $I-V$ curves and reported thickness, the resistivity, $\rho$, and conductivity, $\sigma$, of $\mathrm{CuI}$ thin film were calculated using following equation (1):

$$
\rho=\left(\frac{V}{I}\right) \frac{w t}{l}=\frac{1}{\sigma}
$$

where $V$ is supplied voltage, $I$ is measured current, tis the film thickness, $w$ is the electrode width, and $l$ is the length between electrodes. Figure 3 shows the conductivity of $\mathrm{CuI}$ films in dark and under illumination condition deposited at different deposition condition and concentration. The conductivity value obtained in this work was $5.65,0.69,0.26,0.66,0.63 \mathrm{~S} \mathrm{~cm}^{-1}$. It could be concluded that the conductivity of the thin films decreased with the increase of molar concentration up to $0.5 \mathrm{M}$. There seems to exist an inconsistency between the concentration and the conductivity. The reduction of conductivity at higher concentration contradicts from usual cases where conductivity should increased at higher concentration due to the existence more concentrated $\mathrm{Cu}^{2+}$ ions in films which then significantly increased the grain size. This might be due to the incomplete crystallization or pyrolysis of the precursor at higher concentration due to increased amount of solute with constant substrate temperature for all deposition of different concentrations. Huang and Meng had discussed in detail the effect of grain size the resistivity [23]. They said that 


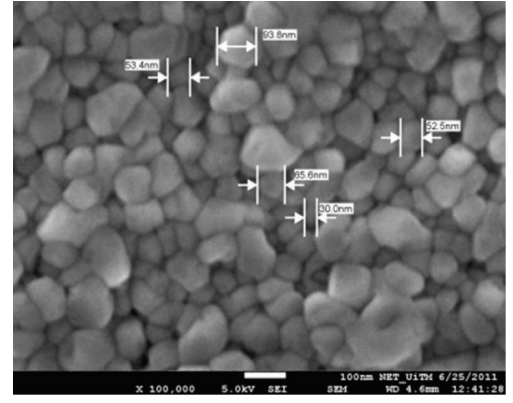

(a)

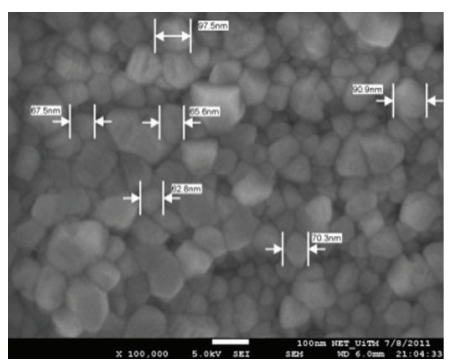

(d)

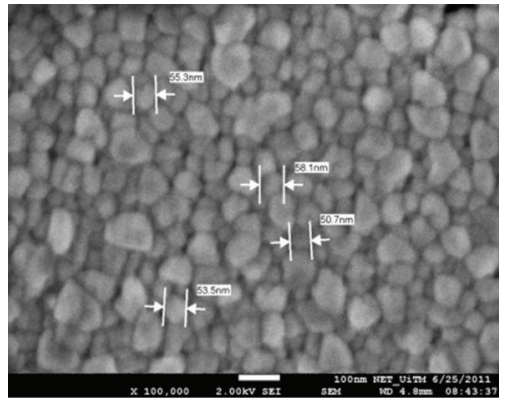

(b)

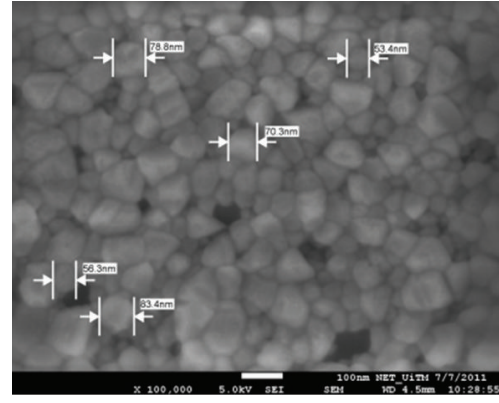

(c)

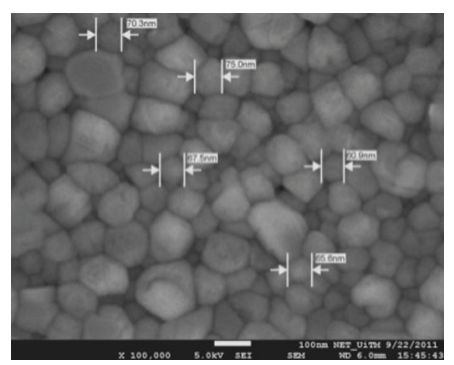

(e)

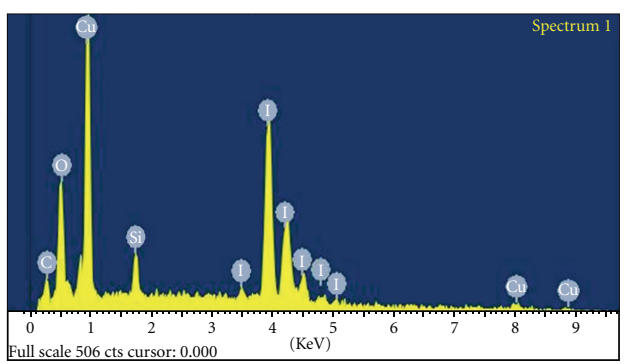

(f)

Figure 2: FESEM images of CuI films at (a) $0.05 \mathrm{M}$, (b) $0.075 \mathrm{M}$, (c) $0.1 \mathrm{M}$, (d) $0.25 \mathrm{M}$, (e) $0.5 \mathrm{M}$ solution concentration, and (f) EDX pattern of the CuI films.

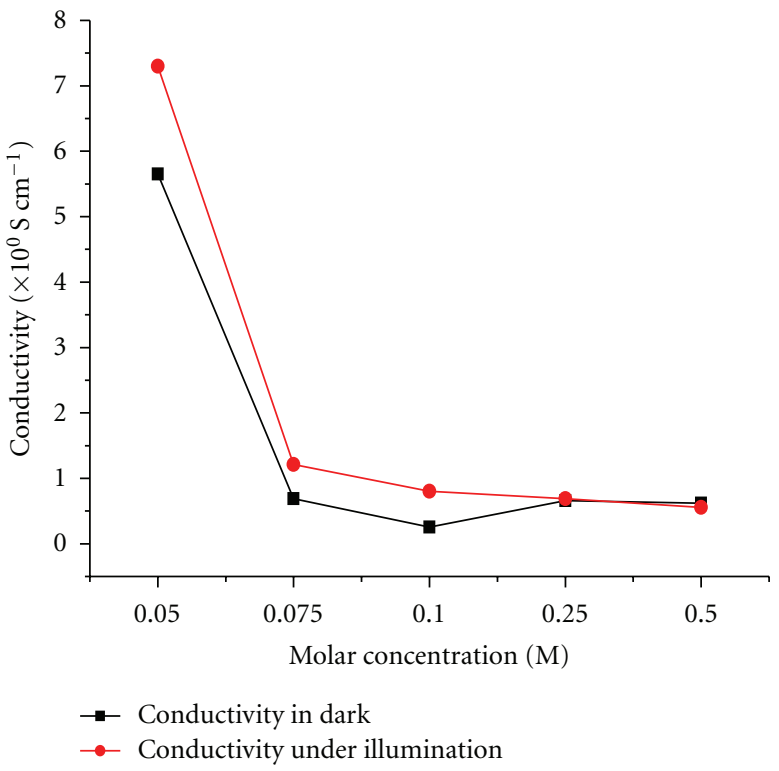

FIGURE 3: Conductivity of CuI films at different solution concentration for in dark and under illumination condition.

the increase in grain size will reduce the carrier concentration and hence increase the resistivity. The resistivity obtained by using this technique is about $10^{-1}$ to $10^{0} \Omega \mathrm{cm}$ which is much lower than resistivity reported using vacuum technology such as pulse laser deposition (PLD). The CuI deposition using PLD done by Sirimanne et al. exhibits a high resistivity of about $10^{3} \Omega \mathrm{cm}$ while Zhu and Zhao obtained $10^{-1} \Omega \mathrm{cm}$ $[24,25]$. The CuI thin film conductivity being also observed under illumination condition which shows similar trend as in dark with higher conductivity was noted. This behavior indicated photoresponse characteristics for the thin films. Therefore, higher $\mathrm{p}$-type conductivity which means higher hole concentration and the photoresponse characteristics shown by $\mathrm{CuI}$ thin films deposited by mister atomizer is suitable to be applied in solid state DSSC application.

3.3. Optical Properties. Figure 4 shows the transmittance spectra of $\mathrm{CuI}$ thin films at different solution concentration. The wavelength is taken at the range between 300 to $1000 \mathrm{~nm}$. The result shows that all the thin films exhibit very low transparency of less than 50\%. Currently, the transmittance of CuI thin films deposited by spraying technique is still under optimization process. The transmittance increases form $0.05 \mathrm{M}$ to $0.1 \mathrm{M}$ and then significantly decreases to $0.5 \mathrm{M}$. In the case of $0.05 \mathrm{M}$ to $0.1 \mathrm{M}$, the increment of transmittance can be related to its surface morphology, where from the FESEM images, the surface becomes smoother up to $0.1 \mathrm{M}$. The decrease of the optical transmittance of $\mathrm{CuI}$ films at high molar concentrations $(0.25 \mathrm{M}$ to $0.5 \mathrm{M})$ was due to optical increased of scattered light at the grain boundaries. In addition, it also could be observed that a sharp absorption edge at wavelength of about $410 \mathrm{~nm}$ indicates the absorption properties of $\mathrm{CuI}$ at visible range.

Figure 5 shows the absorption coefficient $\left(\alpha^{2}\right)$ against the photon energy $(h v)$ for CuI films deposited at different solution concentration. The absorption coefficient, $\alpha$, was 


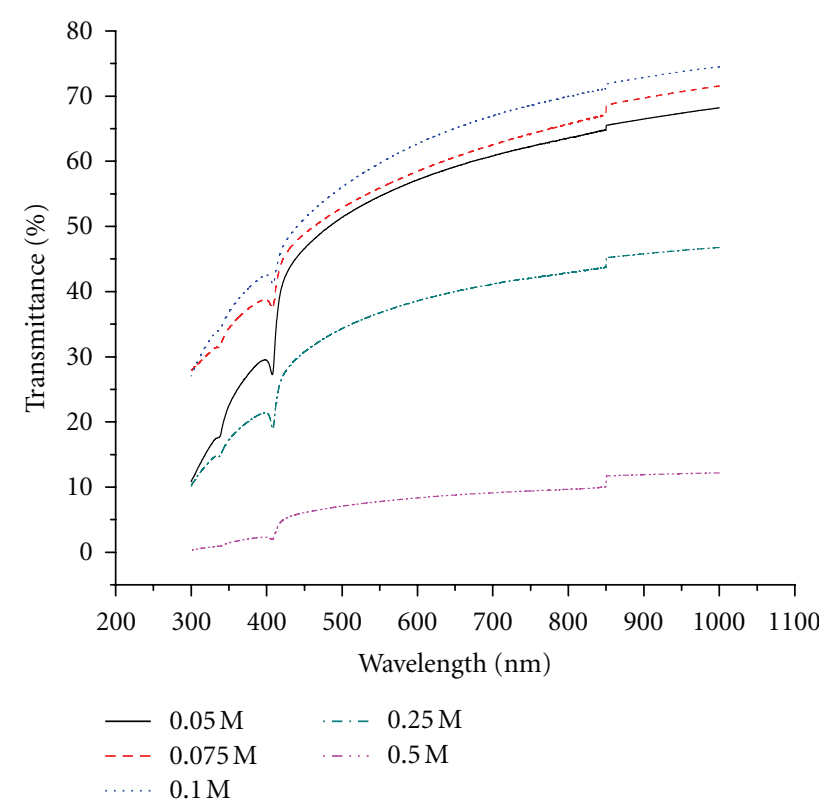

Figure 4: Transmittance of CuI films at different solution concentration.

calculated by using Lambert's law as shown in following equation:

$$
\alpha=\frac{1}{t} \ln \frac{1}{T}
$$

where $t$ is the thin film thickness and $T$ is the transmittance spectra of the thin films. Then, from the absorption coefficient the band gap can be obtained either the films have direct or indirect band gap by plotting of $(\alpha h \nu)^{2}$ and $(\alpha h \nu)^{1 / 2}$ versus $(h v)$. In this research, $(\alpha h \nu)^{2}$ versus $(h v)$ gives better linearity and therefore all the CuI films films have a direct band transition as shown in Figure 5.

It can be observed that the optical band gap of the films decreased from $2.92 \mathrm{eV}$ to $2.83 \mathrm{eV}$ for concentration $0.05 \mathrm{M}$ to $0.1 \mathrm{M}$. The decrease in band gap of CuI films may be due to the enhancement in the crystalline quality of the films and increase of grain size. The high band gap at small crystallite size is attributed to the quantum confinement effect. The quantum confinement effect is where the spacing between the energy levels increases as the nanocrystallite size is decreased [26]. The overall band gap deposited by mister atomizer is smaller than the reported band gap of $3.1 \mathrm{eV}$ [27]. The smaller band gap gives better energy utilization for a longer wavelength which is at the blue part of the solar spectrum.

\section{Conclusions}

The growth of CuI by spraying method is significant to provide fine particle and nanoparticle (below $100 \mathrm{~nm}$ ) thin films. The structural, electrical, and optical properties of the films at different solution concentration were investigated. The XRD result shows strong (111) orientation of $\mathrm{CuI}$ thin film which behaves as $\gamma$-phase with p-type semiconductor

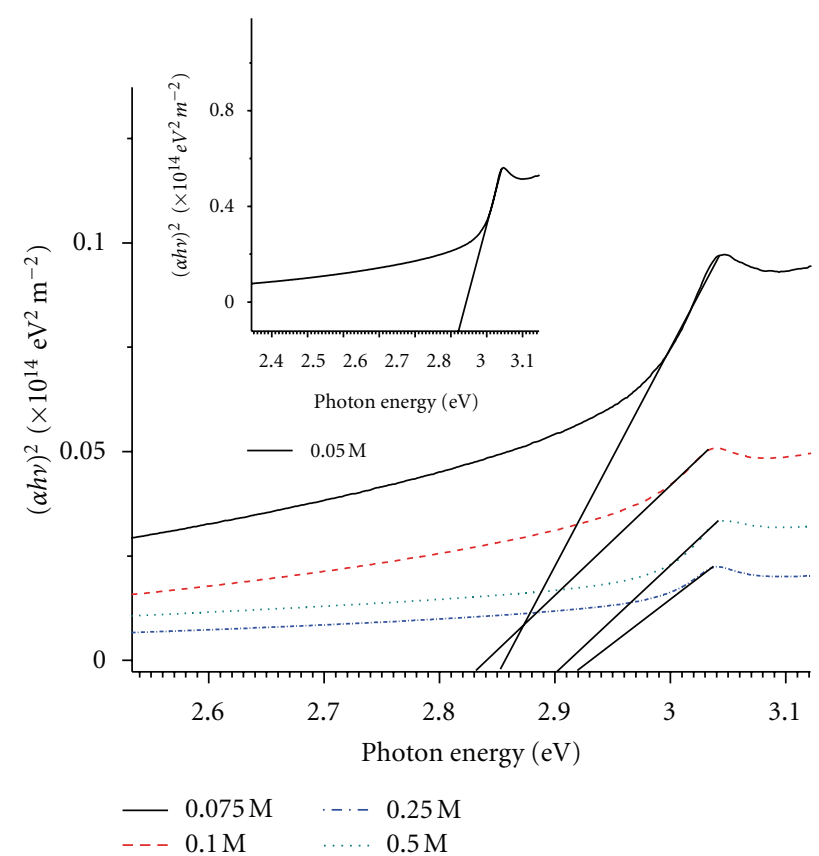

Figure 5: Tauc's plot of CuI films at different solution concentration.

behavior. The smallest crystallite size was obtained for thin film deposited at $0.05 \mathrm{M}$ solution concentration which is $6.40 \mathrm{~nm}$. From FESEM measurement, the surface morphology and grain sizes were determined. The nanostructured CuI film has been successfully deposited by mister atomizer technique with particle size approximately between $30 \mathrm{~nm}$ to $80 \mathrm{~nm}$. The variation of CuI particle size was due to the agglomeration of smaller particles. The conductivity of $\mathrm{CuI}$ films is greatly improved in dark and under illumination condition of about $10^{0} \mathrm{~S} \mathrm{~cm}^{-1}$ which is higher than those deposited by high-vacuum deposition method. The CuI thin films show good photoresponse characteristics which are suitable to be used in solar cell application. The band gap observed is lower than the reported band gap of $3.1 \mathrm{eV}$ which is around $2.9 \mathrm{eV}$. The smaller band gap gives better utilization for bigger solar cell spectrum. Therefore, this technique is very reliable in producing nanostructured and uniform films with low-cost deposition method for fabrication of hole transport material for solid state dye sensitized solar cells application.

\section{Acknowledgments}

Many thanks to Universiti Tekonologi Mara (UiTM), Ministry of Higher Education (MOHE), and Research Management Institute (Excellence Fund (600-RMI/ST/DANA 5/3/Dst (397/2011))), UiTM for the financial support.

\section{References}

[1] B. O’Regan and M. Gratzel, "Low cost and highly efficient solar cells based on the sensitization of colloidal titanium dioxide," Nature, vol. 353, pp. 737-740. 
[2] B. Li, L. Wang, B. Kang, P. Wang, and Y. Qiu, "Review of recent progress in solid-state dye-sensitized solar cells," Solar Energy Materials and Solar Cells, vol. 90, no. 5, pp. 549-573, 2006.

[3] A. R. S. Priya, A. Subramania, Y. S. Jung, and K. J. Kim, "High-performance Quasi-solid-state dye-sensitized solar cell based on an electrospun PVdF-HFP membrane electrolyte," Langmuir, vol. 24, no. 17, pp. 9816-9819, 2008.

[4] C. Olson, D. Veldman, K. Bakker, and F. Lenzmann, "Characterization of the pore filling of solid state dye sensitized solar cells with photoinduced absorption spectroscopy," International Journal of Photoenergy, vol. 2011, Article ID 513089, 11 pages, 2011.

[5] Y. Zhenzhen, C. P. Katherine, L. Di-Jia, R. Yang, and X. Tao, "Solid dye-sensitized solar cells prepared through a counter strategy for filling of solid hole transporter," Journal of Renewable and Sustainable Energy, vol. 3, Article ID 063101, 2011.

[6] V. P. S. Perera and K. Tennakone, "Recombination processes in dye-sensitized solid-state solar cells with $\mathrm{CuI}$ as the hole collector," Solar Energy Materials and Solar Cells, vol. 79, no. 2, pp. 249-255, 2003.

[7] K. Tennakone, G. R. R. A. Kumara, A. R. Kumarasinghe, K. G. U. Wijayantha, and P. M. Sirimanne, "Dye-sensitized nanoporous solid-state photovoltaic cell," Semiconductor Science and Technology, vol. 10, no. 12, pp. 1689-1693, 1995.

[8] G. P. Smestad, S. Spiekermann, J. Kowalik et al., "A technique to compare polythiophene solid-state dye sensitized $\mathrm{TiO}_{2}$ solar cells to liquid junction devices," Solar Energy Materials and Solar Cells, vol. 76, no. 1, pp. 85-105, 2003.

[9] K. Tennakone, V. P. S. Perera, I. R. M. Kottegoda, and G. R. R. A. Kumara, "Dye-sensitized solid state photovoltaic cell based on composite zinc oxide/tin (IV) oxide films," Journal of Physics D, vol. 32, no. 4, pp. 374-379, 1999.

[10] D. S. Jung, S. B. Park, and Y. C. Kang, "Design of particles by spray pyrolysis and recent progress in its application," Korean Journal of Chemical Engineering, vol. 27, no. 6, pp. 1621-1645, 2010.

[11] K. H. Wong, K. Ananthanarayanan, S. R. Gajjela, and P. Balaya, "Solid state dye-sensitized solar cell with $\mathrm{TiO}_{2} / \mathrm{NiO}$ heterojunction: effect of particle size and layer thickness on photovoltaic performance," Materials Chemistry and Physics, vol. 125, no. 3, pp. 553-557, 2011.

[12] C. H. B. Ng and W. Y. Fan, "Facile synthesis of singlecrystalline $\mathrm{y}$-cul nanotetrahedrons and their induced transformation to tetrahedral CuO nanocages," Journal of Physical Chemistry C, vol. 111, no. 26, pp. 9166-9171, 2007.

[13] Y. Matsushima, Y. Nemoto, T. Yamazaki, K. Maeda, and T. Suzuki, "Fabrication of $\mathrm{SnO}_{2}$ particle-layer on the glass substrate using electrospray pyrolysis method and the gas sensitivity for $\mathrm{H}_{2}$," Sensors and Actuators B, vol. 96, no. 1-2, pp. 133-138, 2003.

[14] J. Han, J. M. Chen, X. W. Zhou et al., "Efficiency enhancement of solid-state dye sensitized solar cell by in situ deposition of Cul," Surface and Interface Analysis, vol. 40, no. 10, pp. 13931396, 2008.

[15] R. Thiyagarajan, M. Mahaboob Beevi, and M. Anusuya, "Nano structural characteristics of Zicronium Sulphide thin films," Journal of Americal Science, vol. 5, pp. 6-12, 2009.

[16] A. A. Akl, "Effect of solution molarity on the characteristics of vanadium pentoxide thin film," Applied Surface Science, vol. 252, no. 24, pp. 8745-8750, 2006.

[17] K. Tennakone, G. R. R. A. Kumara, A. R. Kumarasinghe, K. G. U. Wijayantha, and P. M. Sirimanne, "Dye-sensitized nanoporous solid-state photovoltaic cell," Semiconductor Science and Technology, vol. 10, no. 12, pp. 1689-1693, 1995.
[18] Y.-H. Yan, Y.-C. Liu, L. Fang, Z.-C. Lu, Z.-B. Li, and S.X. Zhou, "Growth of CuI buffer layer prepared by spraying method," Transactions of Nonferrous Metals Society of China, vol. 21, no. 2, pp. 359-363, 2011.

[19] J. Han, J. M. Chen, X. W. Zhou et al., "Efficiency enhancement of solid-state dye sensitized solar cell by in situ deposition of Cul," Surface and Interface Analysis, vol. 40, no. 10, pp. 13931396, 2008.

[20] G. R. A. Kumara, A. Konno, K. Shiratsuchi, J. Tsukahara, and K. Tennakone, "Dye-sensitized solid-state solar cells: use of crystal growth inhibitors for deposition of the hole collector," Chemistry of Materials, vol. 14, no. 3, pp. 954-955, 2002.

[21] G. R. A. Kumara, S. Kaneko, M. Okuya, and K. Tennakone, "Fabrication of dye-sensitized solar cells using triethylamine hydrothiocyanate as a CuI crystal growth inhibitor," Langmuir, vol. 18, no. 26, pp. 10493-10495, 2002.

[22] A. R. Zainun, M. H. Mamat, U. M. Noor, and M. Rusop, "Particles size and conductivity study of P-Type copper (I) iodide (CUI) thin film for solid state dye-sensitized solar cells," in Proceedings of the Conference on Advanced Materials and Nanotechnology (CAMAN '09), November 2009.

[23] L. Y. Huang and L. Meng, "Effects of film thickness on microstructure and electrical properties of the pyrite films," Materials Science and Engineering B, vol. 137, no. 1-3, pp. 310314, 2007.

[24] P. M. Sirimanne, M. Rusop, T. Shirata, T. Soga, and T. Jimbo, "Characterization of transparent conducting CuI thin films prepared by pulsed laser deposition technique," Chemical Physics Letters, vol. 366, no. 5-6, pp. 485-489, 2002.

[25] B. L. Zhu and X. Z. Zhao, "Transparent conductive CuI thin films prepared by pulsed laser deposition," Physica Status Solidi (A) Applications and Materials, vol. 208, no. 1, pp. 9196, 2011.

[26] K. E. Andersen, C. Y. Fong, and W. E. Pickett, "Quantum confinement in CdSe nanocrystallites," Journal of Non-Crystalline Solids, vol. 299-302, no. 2, pp. 1105-1110, 2002.

[27] W. Sekkal and A. Zaoui, "Monte Carlo study of transport properties in copper halides," Physica B, vol. 315, no. 1-3, pp. 201-209, 2002. 

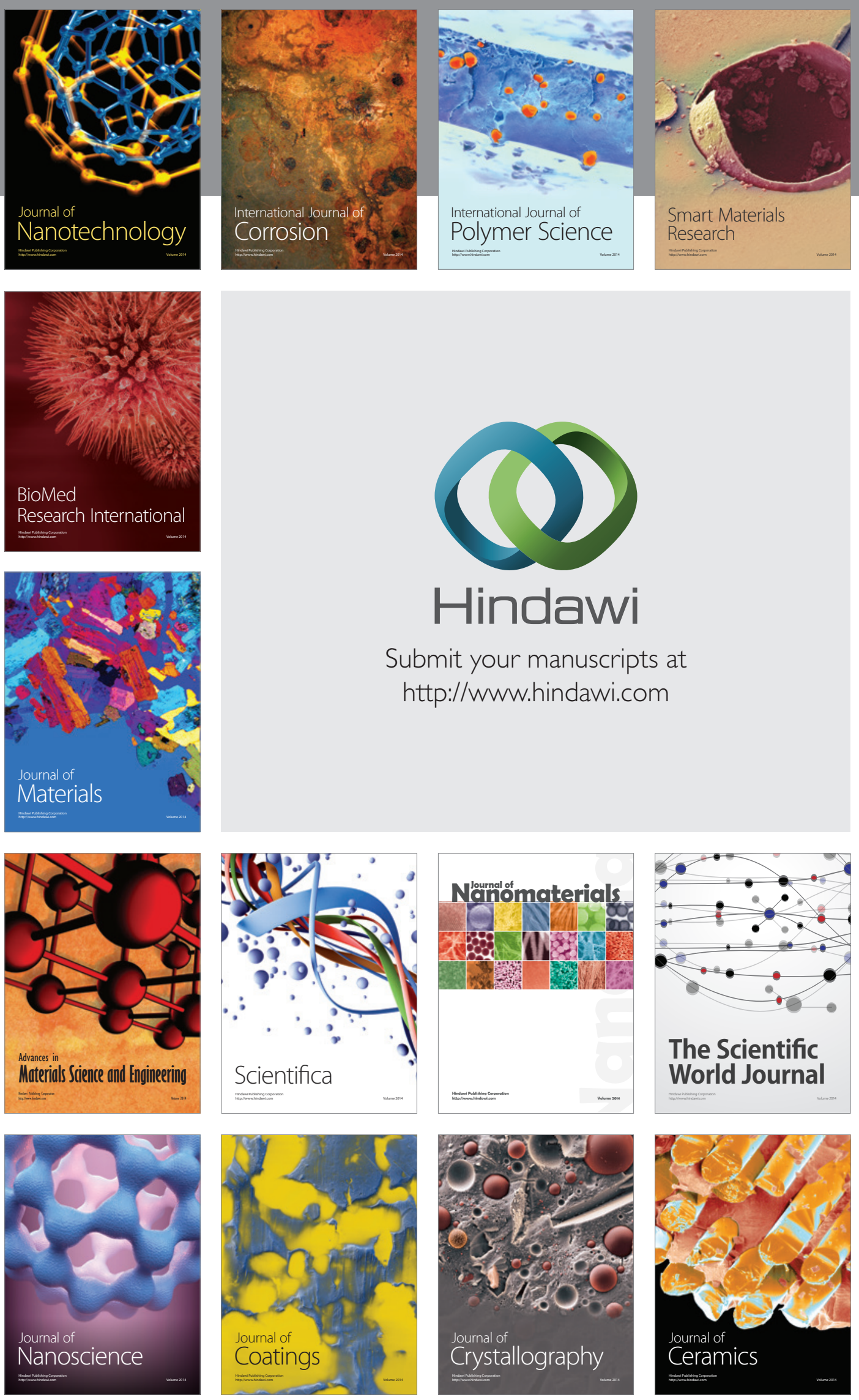

The Scientific World Journal

Submit your manuscripts at

http://www.hindawi.com

\section{World Journal}

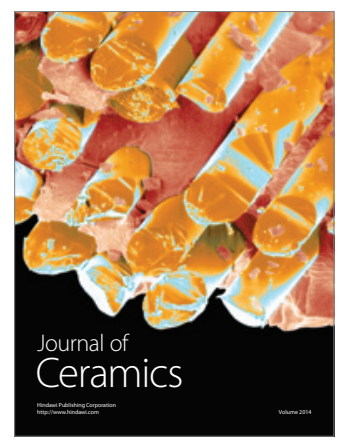

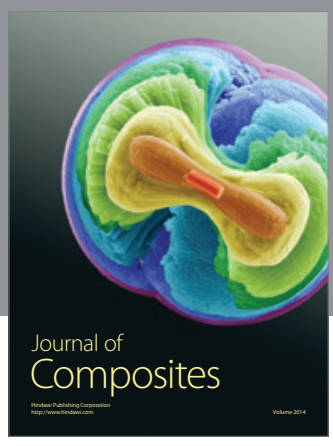
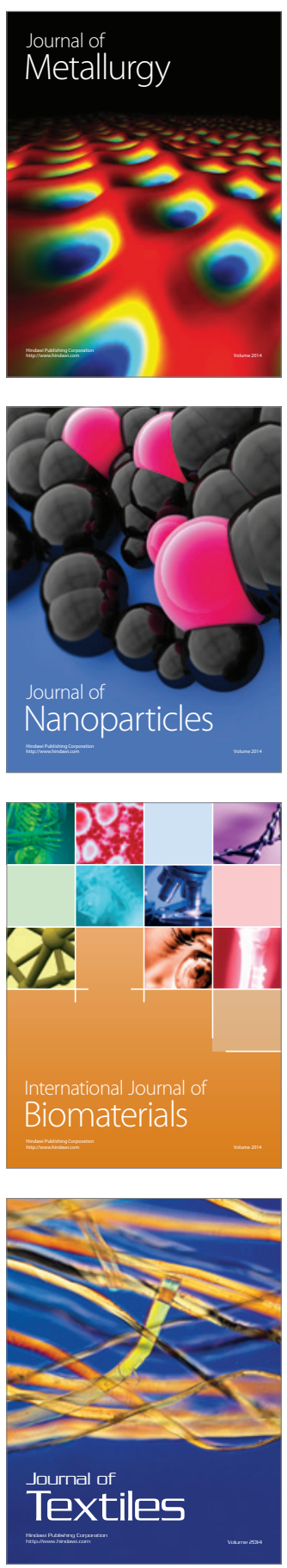